\title{
Antidiabetic and Cytoprotective Effect of Ethanolic Extract of SalaciaNitida Root on Alloxan-Induced Diabetic Rats
}

\author{
Dooka B. $\mathrm{D}^{1}$ and Ezejiofor A. $\mathrm{N}^{1}$ \\ Department of Experimental Pharmacology \& Toxicology, Faculty of Pharmaceutical Sciences, University of \\ Port Harcourt, Rivers State, Nigeria.
}

\begin{abstract}
:
Objective:Many of the available therapies for diabetes have a number of serious adverse effects; therefore the search for more effective and safer hypoglycaemic agents becomes a paramount. This research was set to investigate the antidiabetic potential and cytoprotective effect of ethanolic root extract of Salacianitida on alloxan induced hyperglyceamic rats.

Method:Acute toxicity and phytochemical constituents were evaluated using standardized methods. The study lasted for a period of thirty days comprising of two phases: induction phase and treatment phase. Thirty animals were grouped into five groups of six rats each. Group 1 and 2 serve as normal and toxic control respectively while groups 3, 4, and 5 were treated with 750, 1500mg of S.nitidaand 5mg glibenclamide respectively. The $B G L$, food and fluid intake was monitored daily while the body weight was measured on weekly. The last day of the study after an overnight fast, the animals were loaded with glucose and the OGTT measured prior to and at 30 minutes interval for two hours after which the animals were sacrificed under ether anaesthesia and the organs isolated for histological examination.

Results/Conclusion:The results of the present study indicate that S.nitida possessantidiabetic potentials and cytoprotective effect noted in its significant percentage reduction in the glucose level, slight increase in body weight and restoration of the toxic organs to normal.
\end{abstract}

Keywords:antidiabetic, cytoprotective effect, hyperglyceamic rats, Salacianitida

\section{Introduction}

Diabetes is gradually emerging as a major public health challenge. According to the International Diabetes Federation (IDF), the overall cost assessment for the global prevention and treatment of diabetes will run up to $\$ 490$ billion by 2030 . The prevalence of diabetes is higher in men than in women and diabetes prevalence across the world appears to be increase in the proportion of people greater than 65 years of age (Mohan et al., 2007). Diabetes mellitus has attained a pandemic form. Diabetes is a metabolic disorder of carbohydrate, fat and protein resulting from defects in insulin secretion, insulin action or both (Diabetes Care, 2010). Due to the failure of the modern medicine to address this issues without it inherent problems which result as toxicity to target organ, there arose the need to turn back to nature using herbals which seems more potential with less toxic effect, hence a search by different communities on the possibilities of sourcing antidiabetics from their surrounding.

S.nitida is a plant in the family of Celastraceae. Salacia is a climbing shrub distributed in Sri- Lanka, South-West India, Thialand, Philippines, Java, South Africa and Southeastern part of Nigeria. The plant is locally called "enyimocha" in Ibo and "akorkor in Ogoni. The stem, leaves, rhizomes and roots are harvested from the wild plant and they contain several bioactive metabolites. It flowers fruits throughout the year depending on the humidity of the soil. In the traditional system of medicine, the plants of this genus are being used as acrid, bitter, thermogenic, astringent, anodyne, anti-inflammatory, depurative, emmenagogue, vulnerary, liver tonic and stomachic. They are useful in vitiates conditions of vata, diabetes, hemorrhoids, inflammation, leucorrhoea, leprosy, skin diseases, amenorrhoea, dysmenorrhoea, wounds, ulcers, hyperhydrosis, hepatopathy, dyspepsia, flatulence, colic and spermatorrhoea. Herbal tea containing Salaciareticulata gives a significant reduction in fasting plasma glucose level, glycatedhaemoglobin and body mass index suggesting the use of S.reticulata diet for individuals with mild type 2 diabetes (Kajimotoet al., 2000). The powdered root bark of S.oblonga is used to treat inflammations.

S.nitida is marketed as a starch blocker suggesting that it might help to reduce the body weight. The ethanolic extracts of the roots of S.nitida is used in the treatment of malaria in the southeastern part of Nigeria (Ogbonnaet al., 2008). Therefore this study was set to ascertain the antidiabetic and cytoprotective effect of ethanolic root extract of salacianitida on alloxan-induced diabetic rat. 


\section{Sample Collection}

\section{Experimental}

Plant material used in this study consist of the fresh roots of Salacianitida, collected from a local area in Aluu of Choba community in ObioAkpor Local Government Area of Rivers State, Nigeria in November, 2014.

\section{Sample Identification}

The plant was identified and authenticated by Dr. ChimezieEkeke of the Department of Plant Science and Biotechnology, University of Port-Harcourt, Rivers State, Nigeria.

\section{Sample Processing and Extraction}

After identification, the plant samples were washed with clean water to remove dirt from the roots. The roots were reduced to smaller sizes and sun-dried. About $1000 \mathrm{mg}$ of the powdered root was weighed on an analytical balance and then pulverized using an electric grinder. It was then subjected to solvent extraction by maceration for 96 hours using ethanol $(100 \% \mathrm{v} / \mathrm{v})$. The extract was filtered then carefully evaporated to dryness over a water bath under controlled temperature. The percentage yield was then determined. The obtained extract was stored in a refrigerator.

\section{Animal Care and Handling}

The animals used for the study were 30Wistaralbino rats of both sexes weighing 150-200g procured from the animal house of Department of Experimental Pharmacology\& Toxicology, Faculty of Pharmaceutical Sciences, University of Port Harcourt, Rivers State. They were grouped based on their body weight into five groups of six animals each. They were housed in spacious cages and maintained in standard laboratory conditions. They were fed with standard pelletized feed (manufactured by Premier Feed Mill Co. Ltd) and were allowed water ad libitium. Animal ethics and proper handling methods were strictly adhered to. The bedding of the cages (saw dust) was changed daily and the cages washed and disinfected every other day.

\section{Diabetes Induction Using Alloxan}

Diabetes mellitus was induced in a batch of normoglycemic albino rats using alloxan monohydrate. After acclimatization period and grouping of the animals, the animals were then fasted for 18 hours over night to prepare them for induction. Group 1 was used as control. Group 2, 3, 4, and 5 were made diabetic by single IP injection of alloxan monohydrate $(120 \mathrm{mg} / \mathrm{kg})$ and served as diabetic control, treatment and standard groups respectively. Rats that exhibited plasma glucose levels $>250 \mathrm{mg} / \mathrm{dl}, 7$ days after administration of alloxan were included in the study. Treatment for diabetes (S.nitida extract $750 \mathrm{mg} / \mathrm{kg}$ and $1500 \mathrm{mg} / \mathrm{kg}$ orally) and glibenclamide was initiated from the $7^{\text {th }}$ day of post alloxan administration.

\section{Evaluation of Antidiabetic Activity}

Seven days after alloxan injections, the hyperglycemic rats (blood glucose level $>250 \mathrm{mg} / \mathrm{kg}$ ) were selected for the anti-diabetic study. The animals were divided into various groups for treatment. The different groups are as follows;

- Group 1- non-induced/non-induced rats(normal control)

- Group 2- induced/non- treated rats ( toxic control)

- $\quad$ Group 3- induced $/ 750 \mathrm{mg} / \mathrm{kg}$ of S.nitida

- $\quad$ Group 4- induced $/ 1500 \mathrm{mg} / \mathrm{kg}$ of S.nitida

- $\quad$ Group 5- induced $/ 5 \mathrm{mg} / \mathrm{kg}$ glibenclamide.

These treatment protocols were followed and performed daily for 21 days.

Blood glucose samples were collected by tail tipping method from the overnight fasted rats. The blood glucose level was determined by the glucose strip method, using a glucometer.

\section{Oral Glucose Tolerance Test}

The oral glucose tolerance test was performed in overnight fasted normal, diabetic and treated rats on the $21^{\text {st }}$ day of the treatment. Glucose $(2 \mathrm{~g} / \mathrm{kg})$ was given orally and the blood glucose level was measured at $0,30,60$, 90 and 120 minutes after administration of the glucose.

\section{Histopathological Analysis}

The organs of the animals were harvested afterwards by anaesthetizing using light ether anaesthetic, the extracted organs; liver, kidney and pancreas were weighed to obtain the absolute organ weight, fixed in $10 \%$ formaldehyde and taken for histological analysis. After 72 hours, the organs were dehydrated in graded alcohol, cleared in xylene and embedded in paraffin. The processing of the harvested tissues was done by an autotechnician, the slides were mounted and stained with hematoxylin and eosin (H\&E). The stained sections were morphologically evaluated and pictures of the slides were taken and recorded for comparism. 


\section{Statistical Analysis}

Analysis using Anova software was carried out to examine the statistical significance of differences in the mean levels of the various parameters and biomarkers between the control and test groups.

\section{Results}

Table 1shows theeffect of different doses of the plant extract and glibenclamide on BGL of alloxan induced diabetic rat indicating a dosed dependent significant percentage reduction in blood glucose levels after 14 and 21 days of treatment with the highest reduction of BGL noted when the standard drug GBM was used.

Table 2 shows the effect of different doses of the plant extract and GBM on the body weight of alloxan induced diabetic and treated rats. The table shows significant dose dependent increase in the body weight of the diabetic rats treated with the plant extracts and the standard drug.

Table 3 shows a significant time and dose dependent reduction in blood glucose levels of diabetic rats treated with both plant extract and glibenclamide compared to the untreated rats. Untreated diabetic rats died after 30 minutes because of low glucose tolerance

Resultof the effect of different doses of the plant extract and GBM on the feed and fluid intake, absolute and relative weight of organs of alloxan induced diabetic rat is shown in table 4 . The table shows a significant decrease in feed and fluid intake of diabetic rats treated with the plant extract compared to the untreated diabetic rats.

Figure 1 Photomicrograph of pancreas: figure1a is the photomicrograph of Control slide showing normal pancreatic histology.(1b) is thephotomicrophagh of diabetic induced pancreas of untreated group showing acinar cells but no islet cells.(1c) is the photomicrograph ofdiabetic pancreas treated with $750 \mathrm{mg} / \mathrm{kg}$ of Salacianitida root extract showing acinar cells and a gradual restoration of the islet cells.(1d) is the photomicrograph of the diabetic induced pancreas treated with $1500 \mathrm{mg} / \mathrm{kg}$ of ethanolicSalacianitida root extract showing acinar cells and a higher restoration of islets cells.(1e) is the photomicrograph of the diabetic induced pancreas treated with $5 \mathrm{mg} / \mathrm{kg}$ of glibenclamide, showing acinar cells and restored islet cells.

Figure 2 Photomicrograph of kidney: figure (2a) is photomicrograph of the control slide showing the normal histology of the kidney; (2b) Photomicrograph of the diabetic induced kidney of untreated group showing tubular distortion and severe hemorrhage (SHM). 2c) Photomicrograph of diabetic kidney treated with $750 \mathrm{mg} / \mathrm{kg}$ of Salacianitida rootextract showing reduced haemorrhage and restoration of normal histology, also seen were the glomeruli and renal tubules. 2d) Photomicrograph of the kidney treated with $1500 \mathrm{mg} / \mathrm{kg}$ of Salacianitida rootextract showing reduced haemorrhage and restoration to normal histology. 2e) Photomicrograph of the kidney treated with $5 \mathrm{mg} / \mathrm{kg}$ of glibenclamide showing full restoration of normal histology.

Figure 3 Photomicrograph of liver: (3a) is the control slide showing normal histology of the liver. (3b) Photomicrograph of diabetic liver showing hepatocyte injury, inflammatory cells and sinusoidal haemorrhage. 3c) Photomicrograph of the diabetic liver treated with $750 \mathrm{mg} / \mathrm{kg}$ of Salacianitida rootextract still showing inflammatory cells. 3d) Photomicrograph of diabetic liver treated with $1500 \mathrm{mg} / \mathrm{kg}$ of Salacianitida root extract showing reduced inflammatory cells. 3e) Photomicrograph showing restoration to normal of liver histology after treatment with $5 \mathrm{mg} / \mathrm{kg}$ of glibenclamide. No observed inflammatory cells or histologic change.

\section{Discussion}

The management of diabetes with medications devoid of any side effects is still a major challenge to the medical system. This concern has led to an increase demand for natural products with antihyperglycemic activity, and fewer side effects. In this study, the results obtained suggest that the ethanolic extract of the root of Salacianitida exhibits dose dependent anti-diabetic property and tissue protective effects. Acute toxicity testing of the ethanolic extract of roots of Salacianitida suggests that the lethal dose is greater than $5000 \mathrm{mg} / \mathrm{kg}$ as there were no incidence of abnormalities, gross lesions, body weight changes and mortality observed in the albino rats when the dose of $5000 \mathrm{mg} / \mathrm{kg}$ plant extract was administered. The roots of this plant can be said to be relatively safe (Lorke, 1983).

The phytochemical screening of the ethanolic extractof Salacianitida root revealed the presence of alkaloids, cardiac glycosides, saponins, tannins, flavonoids, phenolic compounds, terpenoids, phlobotannins and carbohydrates. Some of these phytocomponents may cause hypoglycaemic effect in diabetic rats. Studies have shown that such biological activityhypoglycaemic effect might manifest due to the presence of flavonoids, alkaloids, steroids and quinones (Sanders et al., 2001; Ghosh and Konishi, 2007). Also, saponins have been reported to exhibit hypoglycaemic activity which may have inhibitory effects on liver (Nakashima et al., 1993).

The ethanolic extract of Salacianitidaroot exhibited a dose dependent hypoglycaemic property as shown in table Table 1. The result shows that the ethanolic extract of the plant acted on the blood glucose, exhibiting potential glucose tolerance effect and is concordance with the report of Singh (2011). This is reflected in the significant decrease in the blood glucose levels of the diabetic rats treated with S.nitidaextract and 
glibenclamide compared to the blood glucose levels of the untreated diabetic rats. Plants may act on blood glucose through different mechanisms, some of them may have insulin-like substances (Chakravarthyet al., 1980), stimulation of $\beta$-cells to produce more insulin (Ananthanet al., 2004; Ayodhya et al 2010; Chauhan et al 2010, Anand et al 2010), while others may increase $\beta$-cells in the pancreas by activating the regeneration of pancreatic cells (Bopannaet al., 1997; Chorvathovaet al., 199t al 20103, Rao et al 2001). Plant fibres may also interfere with carbohydrate absorption, thereby affecting blood glucose (Subramoniam, 1996). Natural products having antidiabetic potential act through the following mechanisms:-Drugs acting like insulin (insulinomimetics); drugs acting on insulin secreting beta cells (secretagogues); drugs modifying glucose utilization; drugs regenerating and/or repairing pancreatic beta cells; drugs preventing pathological conversion of starch to glucose by inhibition of beta-galactosidase, alpha-glucosidase and alpha-amylase; drugs preventing oxidative stress that is possibly involved in pancreatic beta cell dysfunction found in diabetes (Jarald, 2008).

Diabetic rats exhibited significant decrease in body weight; however, treatment with S.nitida root extracts restored the body weights to near normal levels. Weight gains were lesser in diabetic rats treated with S.nitidathan in those treated with glibenclamide. Improvement of body weight of the diabetic rats treated with the plant extract may be due to the antidiabetogenic effect of S.nitida, as type 1 diabetic condition is associated with loss of body weight.

The supplementation of S.nitidaimproved the glucose tolerance in the fasted treated rats (Table 3 ). From the table, diabetic rats treated with the plant extracts showed a significant reduction in glucose induced hyperglycaemia to near normal levels, while all untreated diabetic rats died at 60 minutes suggesting their low tolerance to glucose.

An evaluation of the absolute organ (Pancreas, Kidney and Liver) weight of the alloxaninduced diabetic rats (Table 4) revealed a significant decrease in the weight of the organs of rats treated with ethanolic root extract of S.nitida and glibenclamide compared to the weights of the organ of the untreated rats. The alteration in overall organ-body weight ratio is an indication of impairment in the normal functioning of the organs.

Also, the feed and fluid intake of diabetic rats was affected by the ethanolic root extract of Salacianitida on the feed and fluid intake on diabetic rats (Table 4). The table shows a dose dependent significant decrease in the feed and fluid intake of diabetic rats treated with S.nitidacompared with the untreated diabetic rats. However a slight but not significant increase was observed in the feed and fluid intake levels when compared to the control. Improvement in the feed and fluid intake of the diabetic rats treated with the plant extract further supports the antidiabetogenic effect of S.nitida in the management of diabetes. The reduction in feed and fluid intake in diabetic rats treated with $5 \mathrm{mg} / \mathrm{kg}$ glibenclamide was slightly higher than the group treated with $1500 \mathrm{mg} / \mathrm{kg}$ S.nitida.

Because appropriate morphological studies are useful for the anatomical localization of action of toxin (Sagaret al., 2010), functional studies in toxicology was coupled with appropriate histological studies. The photomicrograph of the pancreas of the untreated diabetic rats shows degeneration of the pancreatic islet cells (figure 1b). This degeneration of the pancreatic islet cells will cause a rise in blood glucose level and poor utilization of glucose leading to hyperglycemia. The photomicrograph of the pancreas of treated diabetic rats (figures 1c, 1d and 1e) shows that treatments with the extracts and glibenclamide caused a regeneration of the pancreatic islet cells. Comparing figures $1 \mathrm{c}$ and $1 \mathrm{~d}$, it is observed that when a higher concentration $(1500 \mathrm{mg} / \mathrm{kg})$ of the extract was given, a greater restorative effect was shown on the islet cells than when the lower dose $(750 \mathrm{mg} / \mathrm{kg})$ was used.

The photomicrographs of the kidney of the control (non-diabetic group) in figure $2 \mathrm{a}$ show that the kidney of the non-diabetic rats were normal, showing numerous glomerulus, renal tubules and blood vessels. However, the photomicrograph of the untreated diabetic rats (figure $2 \mathrm{~b}$ ) shows severe haemorrhage and distortion of renal tubules. The different doses of the extracts $750 \mathrm{mg} / \mathrm{kg}$ (figure $2 \mathrm{c}$ ) and $1500 \mathrm{mg} / \mathrm{kg}$ (figure $2 \mathrm{~d}$ ) showed normal histological features, with the restorations close to normal when $1500 \mathrm{mg} / \mathrm{kg}$ dose of extract is used.

The photomicrograph of the liver of non-diabetic rats (figure 3a) shows normal hepatocytes, central vein and sinusoids as expected. While the photomicrograph of the liver of untreated diabetic rats show histological changes in the liver. Alloxan induced inflammations as a collection of inflammatory cells were seen together with sinusoidal haemorrhage and hepatocyte injury (fig 3b). However, administering $750 \mathrm{mg} / \mathrm{kg} \mathrm{dose} \mathrm{of}$ the extract reduced the inflammation slightly (figure 3c), while a $1500 \mathrm{mg} / \mathrm{kg}$ dose resulted in more pronounced reduced inflammation and no haemorrhage (figure 3d). Treatment with $5 \mathrm{mg} / \mathrm{kg}$ of glibenclamide resulted in restoration to a normal liver histology (figure 3e). Results obtained in the histology studies suggest that S.nitida root extract is non-toxic to the kidney and liver at all doses used and under a prolonged usage.

Conclusion: in conclusion, results from both the histological and the toxicological studies all support the use of the roots of Salacianitida in the management of diabetes. 


\section{References}

[1]. Agbaje EO, Adeneye AA, Daramola AO. Biochemical and toxicological studies of aqueous extract of Syzigiumaromaticum (L.) Merr and Perry (Myrtaceae) in rodents. African Journal of Traditional, Complementary and Alternative Medicine. 2009;6(3):241254.

[2]. American Diabetes Association, (2010). Diagnosis and classification of diabetes mellitus. Diabetes Care, 27.562-569.

[3]. Anand P., Murali K.Y, Tandon V, Murthy PS, Chandra R. Insulinotropic effect of cinnamaldehyde on transcriptional regulation of pyruvate kinase, phosphoenol pyruvate carboxykinase and GLUT4 translocation in experimental diabetic rats. ChemBiol Interact. 2010; $186(1): 72-81$.

[4]. Ayodhya S., Kusum S., Anjali S., (2010). Hypoglycaemic activity of different extracts of various herbal plants. Singh. Int J. Ayurveda Res Pharm; 1(1):212-224.

[5]. Bopanna, K.N., J. Kannan, S. Gadgil, R. Balaram and S.P. Rathod, 1997. Antidiabetic and antihyperlipidaemic effects of neem seed kernel powder on alloxan diabetic rabbits. Indian J. Pharmacol., 29: 162-167.

[6]. Chakravarthy, B.K., G. Saroj, S.S. Gambhir and K.D. Gode, 1980. Pancreatic beta cell regeneration - A novel antidiabetic mechanism of Pterocarpusmarsupiumroxb. Ind. J. Pharmacol., 12: 123-127.

[7]. Chauhan A, Sharma PK, Srrivastava P, Kumar N, Deuhe R. Plants having potential antidiabeticactivity:areview.Der Pharm Lett. 2010; 2(3): 369-387.

[8]. David N.Ogbonna, Tokuibiye G. Sokari; Anthony A. Agomuoh. Antimalarial activities of some selected traditional herbs from South Eastern Nigeria against Plasmodium Species. 2008

[9]. Ghosh,D; Konishi, T. Anthocyanins and anthocyanin-rich extracts: role in diabetes and eye function. Asia Pac. J. Clin. Nutr., 16 (2007), pp. 200-208.

[10]. Jarald E, Joshi SB, Jain DC. (2008): Diabetes and herbal medicines. Iran J. PharmacolTher, 7(1): 97-106.

[11]. Kajimoto O, Kawamori S, Shomoda Y, Kawahara Y, Hirata H, Takahasi T. (2000).J.Jpn. Soc. Nutri. Food Sci.53:199-205.

[12]. Lorke D. A new approach to practical acute toxicity testing. Arch Toxicol.1983; 54: $275-87$.

[13]. Mohan, V., Sandeep,S., Deepa, R., Shah, B., Varghese, C. Epidemiology of type 2 diabetes 2007, 217-230.

[14]. Nakashima, T., Sekiguchi, T., Kuraoka, A., Fukushima, K., Shibata Y., Komiyama, S., and Nishimoto, T. (1993). Molecular cloning of a human cDNA encoding a novel protein, DAD1, whose defect causes apoptotic cell death in hamster BHK21 cells. Mol. Cell.Biol. 13, 6367-6374.

[15]. Rao, B.K., R Giri, M.M. Kesavulu and C. Apparao, 2001. Effect of oral administration of bark extracts of Pterocarpussantalinus L. on blood glucose level in experimental animals. J. Ethnopharmacol., 74: 69-74.

[16]. Sagar, S., Kaur, M., and Minneman, K.P. (2010). Antiviral lead compounds from marine sponges. Mar Drugs 8, 2619-2638. doi: 10.3390/md8102619.

[17]. Sanders,R.A., Rauscher, F.M., Watkins, J.B. Effects of quercetin on antioxidant defense in streptozotocin-induced diabetic rats. J. Biochem. Mol. Toxicol., 15 (2001), pp. 143-149

[18]. Singh LW. Traditional medicinal plants of Manipur as anti-diabetics. J. Med Plant Res.2011; 5(5): $677-687$ (Ananthanet al., 2004;

[19]. Subramoniam A, PushpangadanP,Rajasekharan S, Evan DA, Latha PG, Valsaraj R. (1996). Effects of Artemisia pallens wall on blood glucose levels in normal and alloxan induced diabetic rats. Journal of Ethnopharmacology.50:13.

[20]. World Health Organization (1999). Definition, diagnosis and classification of diabetes mellitus and complications.

Table1: Effect of ethanolic root extract of S.nitida and glibenclamide on blood glucose level of alloxan induced rat (\% BGL reduction).

\begin{tabular}{|l|l|l|l|l|}
\hline Groups & Day 0 & Day 7 & Day 14 & Day 21 \\
\hline Group1 & $65.25 \pm 4.99$ & $65.00 \pm 4.96$ & $64.20 \pm 5.45$ & $63.45 \pm 9.21$ \\
\hline Group 2 & $273.70 \pm 46.82$ & $390.25 \pm 54.58$ & $461.75 \pm 98.00$ & $481.25 \pm 106.79$ \\
& & $\uparrow 42.58 \%$ & $\uparrow 68.71 \%$ & $\uparrow 75.83 \%$ \\
\hline Group 3 & $471.00 \pm 38.45$ & $407.25 \pm 48.84$ & $311.25 \pm 55.14^{*}$ & $247.00 \pm 40.09 *$ \\
& & $\downarrow 13.54 \%$ & $\downarrow 40.00 \%$ & $\downarrow 41.83 \%$ \\
\hline Group 4 & $416.75 \pm 18.80$ & $327.00 \pm 15.73^{*}$ & $251.00 \pm 23.31^{*}$ & $191.25 \pm 16.15 *$ \\
& & $\downarrow 21.57 \%$ & $\downarrow 39.66 \%$ & $\downarrow 54.11 \%$ \\
\hline Group 5 & $480.25 \pm 54.43$ & $312.25 \pm 9.21^{*}$ & $224.00 \pm 18.66^{*}$ & $114.00 \pm 14.31 *$ \\
& & $\downarrow 35.00 \%$ & $\downarrow 53.36 \%$ & $\downarrow 76.26 \%$ \\
\hline
\end{tabular}

Mean \pm SEM $(\mathrm{n}=6) * \mathrm{p}<0.05$, significantly different compared to the diabetic untreated group. I.C = diabetic induce; $G B M=$ Glibenclamide

Table 2: Effect of ethanolic root extract of $S$. nitida on body weight of alloxan induced diabetic rat for the period of the study (\% increase in BW).

\begin{tabular}{|l|l|l|l|l|}
\hline Groups & Day 0 & Day 7 & Day 14 & Day 21 \\
\hline Group1 & $150.75 \pm 2.5$ & $152.75 \pm 2.22$ & $155.00 \pm 2.45$ & $156.75 \pm 1.89$ \\
\hline Group 2 & $183.50 \pm 2.65$ & $164.00 \pm 5.94$ & $140.75 \pm 7.93$ & $118.75 \pm 8.77$ \\
& & $\downarrow 10.38 \%$ & $\downarrow 23.50 \%$ & $\downarrow 35.11 \%$ \\
\hline Group 3 & $189.75 \pm 2.5$ & $191.75 \pm 2.5^{*}$ & $193.25 \pm 2.06^{*}$ & $195.00 \pm 2.16^{*}$ \\
& & $\uparrow 1.05 \%$ & $\uparrow 1.85 \%$ & $12.77 \%$ \\
\hline Group 4 & $183.00 \pm 2.65$ & $185.75 \pm 1.71^{*}$ & $186.25 \pm 1.5^{*}$ & $188.50 \pm 1.29 *$ \\
& & $\uparrow 1.5 \%$ & $\uparrow 2.05 \%$ & $14 \%$ \\
\hline Group 5 & $186.00 \pm 2.58$ & $190.75 \pm 3.5^{*}$ & $194.75 \pm 3.59^{*}$ & $196.75 \pm 1.71 *$ \\
& & $\uparrow 2.55 \%$ & $\uparrow 4.44 \%$ & $\uparrow .65 \%$ \\
\hline
\end{tabular}

Mean \pm SEM $(n=6) ; *=p<0.05$ significantly different compared untreated group 
Antidiabetic and Cytoprotective Effect of Ethanolic Extract of SalaciaNitida Root on Alloxan-..

Table 3 Effect of ethanolic root extract of salacianitidaon serum oral glucose torelancelevel of alloxan induced diabetic rat (OGTT).

\begin{tabular}{|l|l|l|l|l|}
\hline Groups & Basal & 30 Min & 60 Min & 120 Min \\
\hline Group1 & $70.25 \pm 7.14$ & $72.50 \pm 7.05$ & $71.50 \pm 5.97$ & $71.00 \pm 6.58$ \\
\hline Group 2 & $439.75 \pm 66.43$ & $482.50 \pm 65.67$ & 0.00 & 0.00 \\
\hline Group 3 & $120.00 \pm 8.98^{*}$ & $126.00 \pm 5.72^{*}$ & $123.75 \pm 2.99^{*}$ & $120.75 \pm 2.22^{*}$ \\
\hline Group 4 & $109.75 \pm 10.53^{*}$ & $115.50 \pm 7.85^{*}$ & $113.25 \pm 8.69^{*}$ & $110.75 \pm 8.96^{*}$ \\
\hline Group 5 & $104.50 \pm 5.45^{*}$ & $113.50 \pm 4.65^{*}$ & $108.00 \pm 4.08^{*}$ & $106.00 \pm 3.16^{*}$ \\
\hline
\end{tabular}

Mean $\pm \operatorname{SEM}(\mathrm{n}=5) ; *=\mathrm{P}<0.05$ significantly different compared to the diabetic untreated.

Table 4:Effect of the ethanolic root extract of Salacianitida on the feed and fluid intake, absolute and relative weight of organs.

\begin{tabular}{|c|c|c|c|c|c|c|}
\hline Groups & $\begin{array}{l}\text { IBW (g) } \\
\text { FBW (g) }\end{array}$ & $\begin{array}{l}(A P W)(g) \\
\text { RWP }(\%) \\
\end{array}$ & $\begin{array}{l}\operatorname{ALW}(\mathrm{g}) \\
\operatorname{RWL}(\%)\end{array}$ & $\begin{array}{l}\operatorname{AKW}(\mathrm{g}) \\
\operatorname{RWK}(\%)\end{array}$ & Feed intake (g/d) & Fluid intake $(\mathrm{ml} / \mathrm{d})$ \\
\hline Group1 & $\begin{array}{l}150.75 \pm 2.5 \\
156.75 \pm 1.89\end{array}$ & $\begin{array}{l}0.41 \pm 0.03 \\
0.26 \pm 0.21\end{array}$ & $\begin{array}{l}3.50 \pm 0.08 \\
2.24 \pm 0.18\end{array}$ & $\begin{array}{l}2.25 \pm 0.13 \\
1.44 \pm 0.13\end{array}$ & $36.14 \pm 5.46$ & $81.00 \pm 3.91$ \\
\hline Group 2 & $\begin{array}{l}183.50 \pm 2.65 \\
118.75 \pm 8.77\end{array}$ & $\begin{array}{l}1.35 \pm 0.12 \\
1.14 \pm 0.18\end{array}$ & $\begin{array}{l}6.20 \pm 0.09 \\
5.22 \pm 0.62\end{array}$ & $\begin{array}{l}4.40 \pm 0.18 \\
3.68 \pm 0.19\end{array}$ & $80.14 \pm 4.88$ & $272.43 \pm 17.07$ \\
\hline Group 3 & $\begin{array}{l}189.75 \pm 2.5 \\
195.00 \pm 2.16^{*}\end{array}$ & $\begin{array}{l}0.83 \pm 0.05^{*} \\
0.41 \pm 0.14^{*}\end{array}$ & $\begin{array}{l}4.85 \pm 0.08 * \\
2.49 \pm 0.23 *\end{array}$ & $\begin{array}{l}2.93 \pm 0.13^{*} \\
1.50 \pm 0.06^{*}\end{array}$ & $66.09 \pm 3.96^{*}$ & $145.67 \pm 9.58 *$ \\
\hline Group 4 & $\begin{array}{l}183.00 \pm 2.65 \\
188.50 \pm 1.29 *\end{array}$ & $\begin{array}{l}0.68 \pm 0.12^{*} \\
0.37 \pm 0.05^{*}\end{array}$ & $\begin{array}{l}4.15 \pm 0.13^{*} \\
2.20 \pm 0.09^{*}\end{array}$ & $\begin{array}{l}2.65 \pm 0.17 * \\
1.41 \pm 0.10^{*}\end{array}$ & $57.05 \pm 4.51 *$ & $120.67 \pm 10.05^{*}$ \\
\hline Group 5 & $\begin{array}{l}186.00 \pm 2.58 \\
196.75 \pm 1.71 *\end{array}$ & $\begin{array}{l}0.55 \pm 0.05^{*} \\
0.28 \pm 0.01^{*}\end{array}$ & $\begin{array}{l}3.70 \pm 0.13^{*} \\
1.87 \pm 0.15^{*}\end{array}$ & $\begin{array}{l}2.57 \pm 0.17 * \\
1.31 \pm 0.16^{*}\end{array}$ & $49.14 \pm 3.39^{*}$ & $106.95 \pm 6.34 *$ \\
\hline
\end{tabular}

Mean $\pm \operatorname{SEM}(n=5) ; *=p<0.05$ significantly different compared to the diabetic untreated group.IBW=initial body weight; FBW= final body weight; $\mathbf{A P W}=$ absolute pancreatic weight; $\mathbf{R W P}=$ relative weight of pancreas; $\mathbf{A L W}=$ absolute liver weight; $\mathbf{R W L}=$ relative weight of Liver; $\mathbf{A K W}=$ absolute kidney weight; $\mathbf{R W K}=$ relative weight of kidney
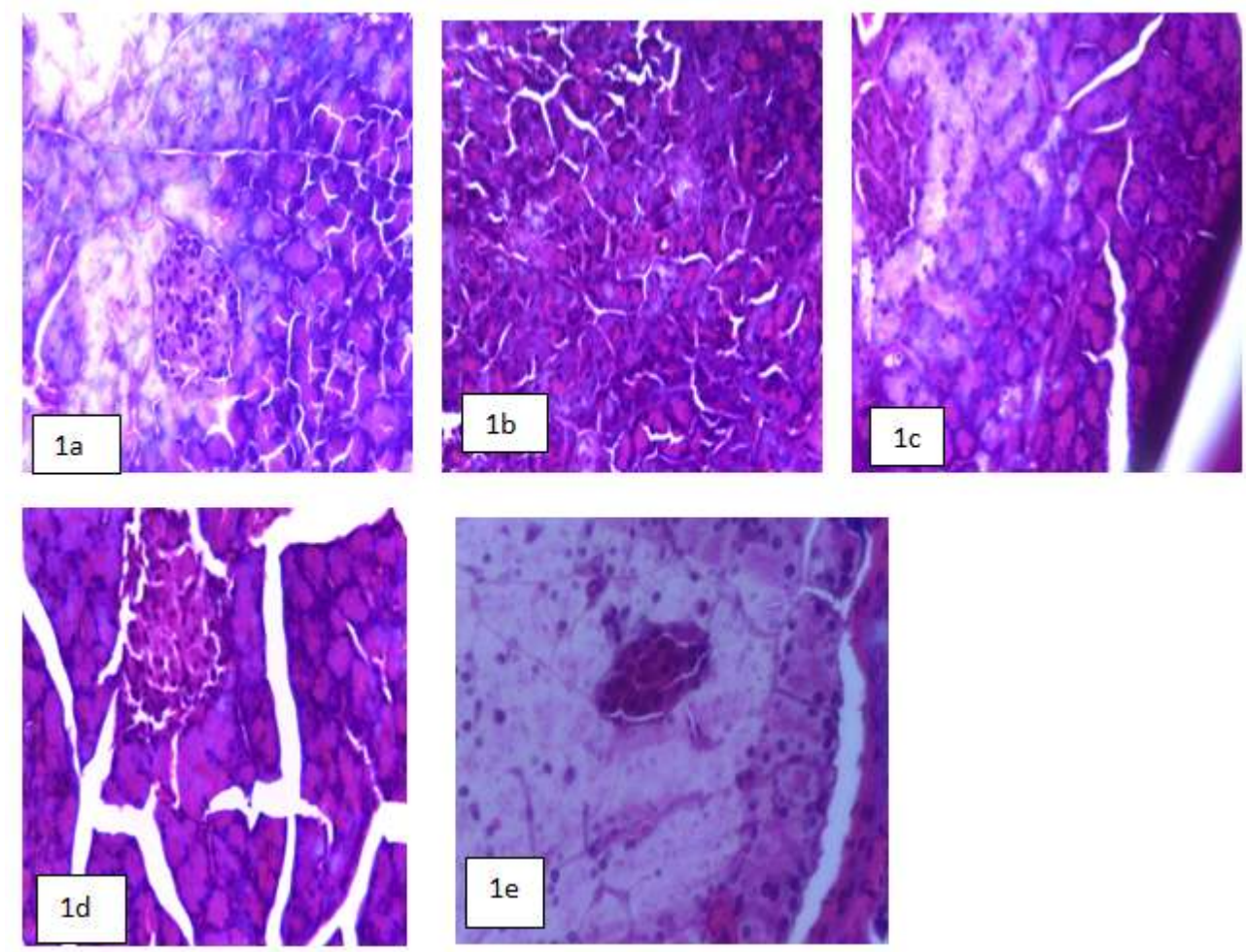

Figure 1: Photomicrograph ofpancreas. All panel stained with H \& E, Magnification X400. (1a)negative controlrat pancreas showing adequate islet cell mass; (1b)positive/diabetic control showing reduced and distorted islet cell which could be due to atrophy and no acinar cells was seen; (1c) induced $+750 \mathrm{mg} / \mathrm{kg}$ Salacianitida showing increased islet cell mass; (1d) induced $+1500 \mathrm{mg} / \mathrm{kg}$ Salacianitida showing adequate islet cell mass and restoration of normal histology of the pancreases; (1e) induced $\pm 5 \mathrm{mg} / \mathrm{kg}$ glibemclamideshowing restoration of normal histology showing a good islet cell mass and acinar cells architecture 

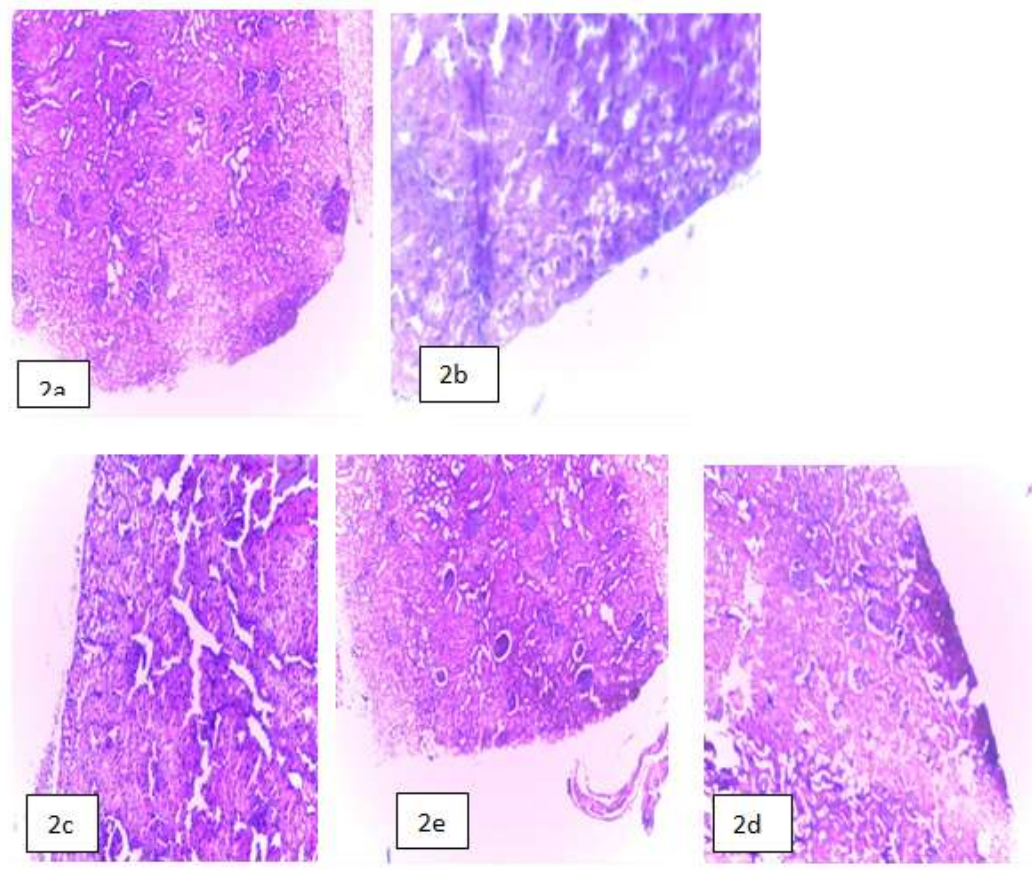

Figure 2: Photomicrograph of kidney. All panel stained with H \& E, Magnification X400. (2a) negative control showing normal histology of kidney with presence of glomeruli and renal tubules; (2b) positive/diabetic control showing distorted glomeruli; (2c) induced $+750 \mathrm{mg} / \mathrm{kg}$ Salacianitida showing no histologic change; (2d) induced $+1500 \mathrm{mg} / \mathrm{kg}$ Salacianitida showing no histologic change; $(2 \mathrm{e})$ induced $+5 \mathrm{mg} / \mathrm{kg}$ glibemclamide showing normal architecture
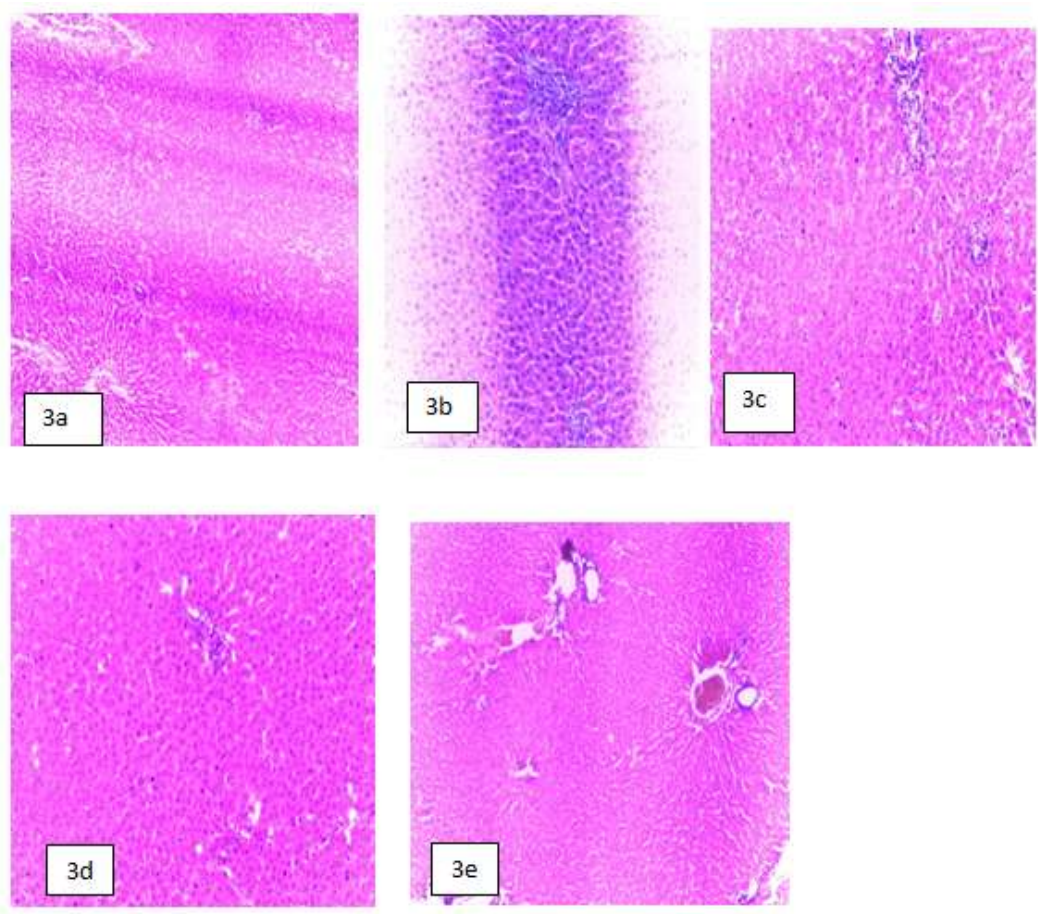

Figure 3: Photomicrograph ofliver. All panel stained with H \& E, Magnification X400. (3a) negative control showing normal hepatocytes with central vein (3b) positive/diabetic control showing necrosis (3c) induced + $750 \mathrm{mg} / \mathrm{kg}$ Salacianitidashowing inflammatory changes and restoration of normal histology; (3d) induced + $1500 \mathrm{mg} / \mathrm{kg}$ Salacianitida showing reduced inflammation and restoration of normal histology; (3e) induced + $5 \mathrm{mg} / \mathrm{kg}$ glibemclamide showing restoration to normal histology evidenced with appearance of hepatocytes with central vein 